\title{
Precision Assessment of UAVRS Based DSM in Disaster Emergency
}

\author{
Yumin Tan1, Lingfeng He1, Linjie Bai² \\ ${ }^{1}$ School of Transporation Science \& Engineering, Beihang University, Beijing, China \\ ${ }^{2}$ State Grid Corporation of China, Shijiazhuang, China \\ Email:07836@buaa.edu.cn, hlingf@sina.com
}

Received 30 July 2016; accepted 26 September 2016; published 29 September 2016

Copyright (C) 2016 by authors and Scientific Research Publishing Inc.

This work is licensed under the Creative Commons Attribution International License (CC BY).

http://creativecommons.org/licenses/by/4.0/

(c) (i) Open Access

\begin{abstract}
Ground control point (GCP) is important for georeferencing remotely sensed images and topographic model. However, considering that GCP collection is sometimes a difficult, time-consuming and expensive task with high resolution (HR) data in remote and harsh environments, today unmanned aerial vehicle based remote sensing (UAVRS) is frequently used in geological disaster emergency monitoring and rescuing for its great advantage in collecting timely onsite images. In this paper, for evaluating the feasibility of the UAVRS in disaster emergency and high cut slope safety monitoring, the digital surface model (DSM) without GCPs based on Structure from Motion (SfM) is accessed, and results showed that the geometric accuracy of DSM was smaller than 1 percent, which prove the usefulness of DSM based on UAVRS in emergency. Comparing to normal disaster emergency, the method without GCPs can be more efficient and save the disaster emergency time by neglecting GCPs measurement.
\end{abstract}

\section{Keywords}

High Cut Slope, Digital Surface Model (DSM), Slope Photography, Geometric Accuracy, Unmanned Aerial Vehicle (UAV)

\section{Introduction}

In recent years, disasters have occurred frequently on high cut slopes located in the Three Gorges Reservoir Area, which resulted in widespread destruction [1] [2]. Because many production and living facilities are located in Three Gorge Reservoir Area, once geological disaster (such as a landslide) happens, heavy economic losses and casualties may be caused. Therefore, the introduction of information technology, which allows analyzing, monitoring and early warning of high cut slope, is very crucial. 
Artificial Slope, shaped by human activity, is called cut slope in the Three Gorges Reservoir. The rock slope which is higher than 15 degrees and the soil slope that is higher than 8 degrees are defined as high side slope, and also called high cut slope in the Three Gorges Reservoir [3]. Due to the large-scale resettlement and reconstruction, a large number of high cut slopes were formed in the Three Gorges Reservoir [1]. Comparing to normal geological bodies, the structure of high cut slopes is more densely distributed, complex smaller. Most of them are formed by artificial excavation, and can be easily changed by human activity [4].

At present, Terrestrial Laser Scanner (TLS), Satellite Based Remote Sensing and UAVRS are introduced to provide data for landslide monitoring and model analysis of high cut slope [5] [6]. However, TLS often has line-of-sight issues, and airborne LIDAR is usually expensive for individual landslide studies [7]. Also, external environment and spatial and temporal resolution can limit the availability of the optical images from satellite remote sensing. Although the space borne laser data can be obtained under all weather conditions and have larger swat range and global coverage, the low image spatial resolution limits its use in landslide and high cut slope monitoring [8]. Meanwhile, because of the large gradient of high cut slopes, it is difficult to have images taken in vertical angle through satellite based remote sensing, leading to space and lose details when modeling the high cut slope.

The UAV based Remote Sensing (UAVRS) differs from TLS, and Satellite Based Remote Sensing and is becoming more and more popular due to the following reasons. Firstly, not only can it solve the problems of severe weather conditions, short sailing time and hazardous geographical environment, but also overcome the difficulties to obtain qualified Satellite based Remote Sensing images due to cloudy and foggy weather. Secondly, it can generate multi-angle and high resolution images [9] [10], which perfectly solve the problems existing in ground remote sensing, including small working range, narrow viewing and heavy workload [11]. In Three Gorges Reservoir, high spatial Satellite Remote Sensing images and ground survey are currently used to monitor high cut slopes, which are insufficient. It is necessary to adopt UAVRS for disaster emergency and high cut slope monitoring.

Many recent studies have shown that landslide and high cut slope monitoring using UAVRS is effective. Li et al. [12] suggested the advantages of UAVRS in monitoring the slope in China. Konstantinos G. et al. [13] used a six-rotor UAV with Gopro Hero 3+ camera to obtain landslide images, and analyzed the disaster by DSM (Digital Surface Model) generated from the images and high accuracy ground control points (GCPs). Also, Darren et al. [14] analyzed landslide in southern Tasmania valley over the years through high accuracy DSMs by high overlay images and GCPs. According to the above-mentioned and some other literatures, DSMs are a very important data source or production in landslide and high cut slope disaster and safety monitoring [15].

We know that the quantity and precision of GCPs will affect the accuracy of produced DSM. However, the GCP collection is a difficult and expensive task with HR data in remote and harsh environments or when cartographic or ground control data do not exist. Therefore, collecting GCPs is sometimes impossible in disaster emergency [16]. Some research about satellite remote sensing has proved the feasibility of no-GCP for building DSM [17], but few publications discuss whether the accuracy of produced DSM from UAVRS is enough for high cut slope emergency. Given these facts, this paper explored building DSMs of high cut slope based on UAVRS without GCPs, and compared the absolute and geometric accuracy of the produced DSM to verify its feasibility.

This paper is organized as follows. Section 2 discussed the methodology, including the experiment field site, equipment, data and method for the construction of DSM. Section 3 discussed the accuracy of DSM with and without GCPs. Section 4 analyzed the DSM and land use/land cover (LULC). Section 5 elaborated the advantages of disaster warning by the DSM without GCPs.

\section{Methodology}

\subsection{Field Site}

Fuling district belongs to the Chongqing City, and is located in Three Gorges reservoir. It is cloudy weather and rains most of the year in Fuling. According to the statistics, there are 375 high cut slopes in Fuling [1], with total length of $45,667 \mathrm{~m}$ and total area of $665,677 \mathrm{~m}^{2}$. Figure 1 shows the location of the experiment area with WGS84 coordinate system (the unique coordinate system in this paper). The top area of the high cut slope is farmland, and the bottom is the road and high buildings. The slope is steep, and the maximum dispersion is greater than $20 \mathrm{~m}$. 


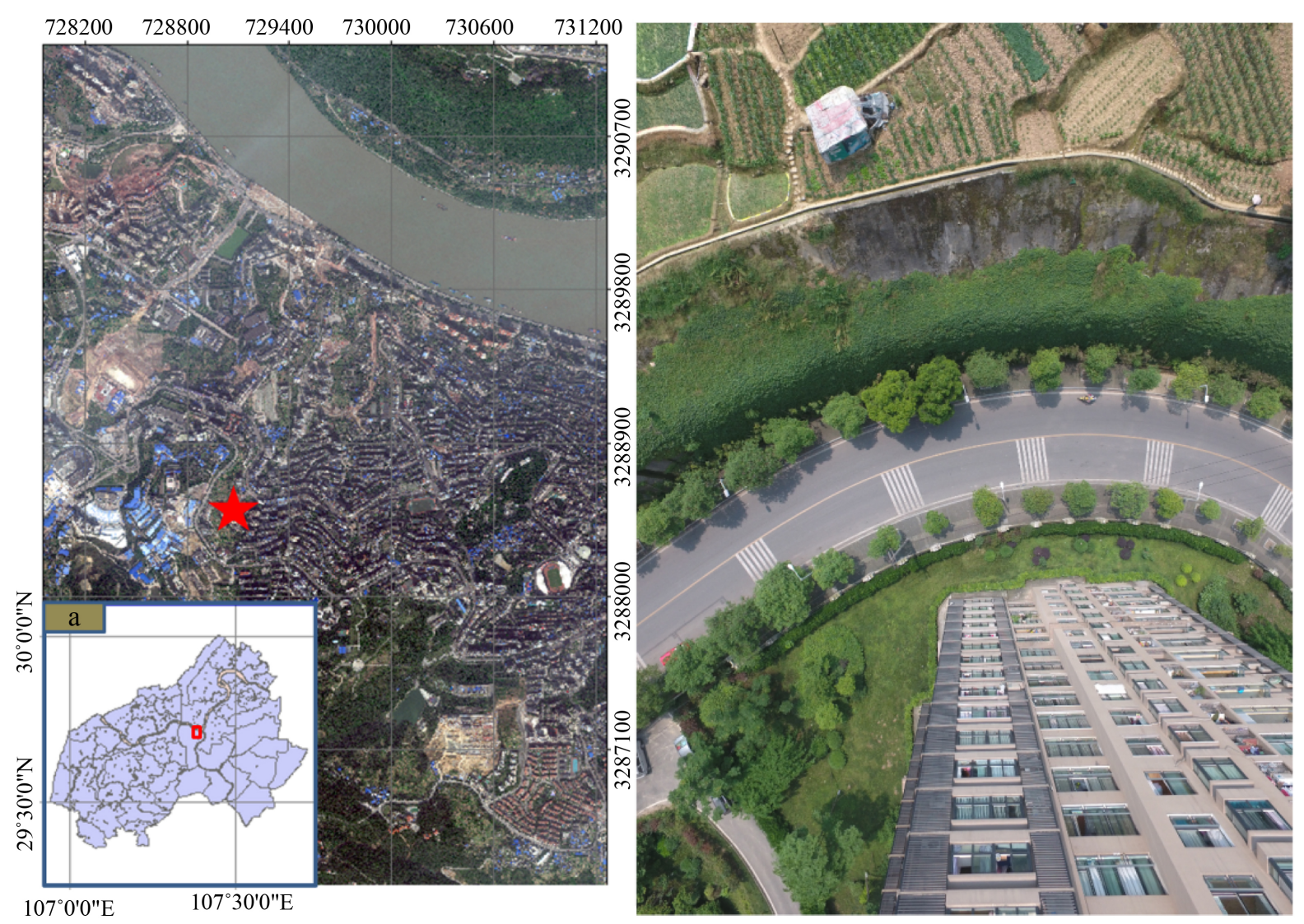

Figure 1. Location map (coordinate system: WGS84 UTM 48N).

\subsection{Equipment}

Because of the excellent handling characteristics, Multi Rotor UAV have become to the major aircraft of aerial photography. In the paper, the Dajiang phantom 4 (see Figure 2) which can be located rapidly by GPS and GLONASS double-satellite positioning system was used, and the camera $\left(2006 \times 1511\right.$ pixels, FOV $94^{\circ} 20 \mathrm{~mm}$, F/2.8 IS lens) was its own of the UAV. However, the positioning system has low accuracy in vertical direction. The Table 1 presents detailed camera parameters.

For this study, we obtained 151 images in direction of $90^{\circ}$ and $45^{\circ}$ (81 images in $90^{\circ}, 70$ images in $45^{\circ}$ ) and the flight heights are $50 \mathrm{~m}$ and $35 \mathrm{~m}$ respectively. Meanwhile, the average ground resolution is about $1.73 \mathrm{~cm}$. Forward overlap rate of images on course line is greater than $80 \%$ (The previous experiment showed that the images whose Overlap rate on course line is greater than $80 \%$ can build complete 3D model).

In order to check the feasibility of building DSM by high overlay images, according to traditional way, we measured some GCPs to build high accuracy DSM. Also, we can compare accuracy of DSM with GCPs and accuracy of DSM without GCPs. The 9 GCPs consist of the corners of road (see Figure 3), scattered around the high cut slope area and then measured by a Trimble R8 GNSS RTK GPS. Depending on base station in Chongqing City, it provided GCPs coordinates with an absolute accuracy of $2 \mathrm{~cm}$ in vertical direction and $1 \mathrm{~cm}$ in horizontal direction by dynamic measurement.

\subsection{D Reconstruction}

The photogrammetric software package Pix $4 D$ has been used for experiment. Pix $4 D$ is professional processing software, and can be applied for converting thousands of images, taken by lightweight unmanned aerial vehicle or aircraft into geo-referenced 2D or 3D surface models and point clouds. The SfM algorithm implemented by PIX4Dmapper was used in this work to generate 2 DSMs of the study area to be successively with the high accuracy GCPs. The reconstruction of DSM can be divided into the following steps. 


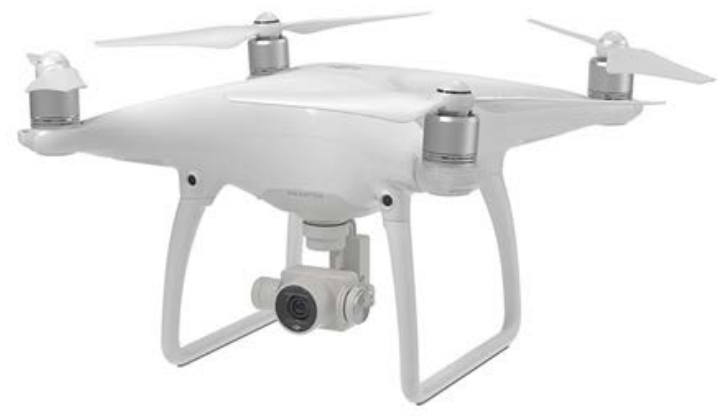

Figure 2. Presentation of DJI PHANTOM 4 and the camera.

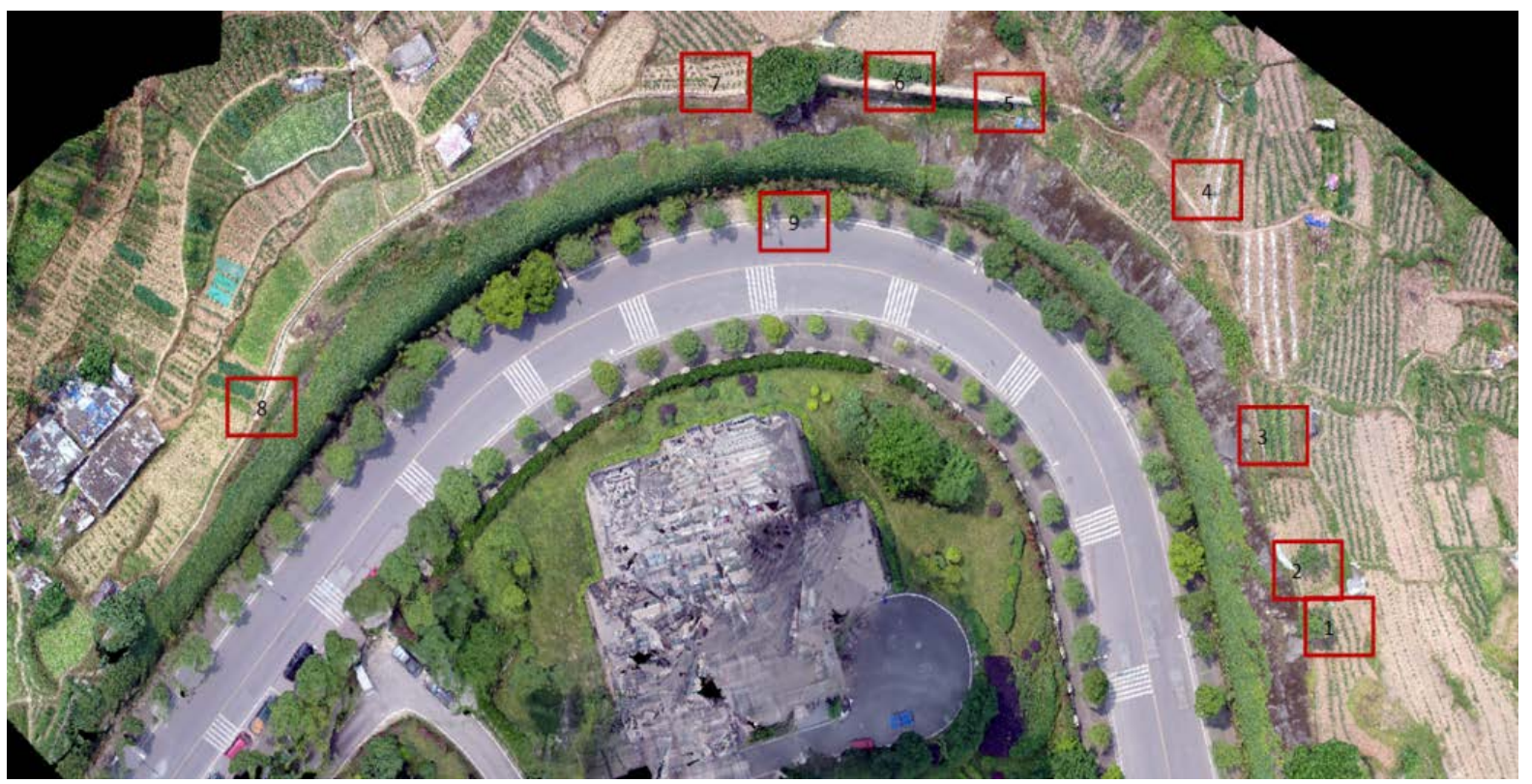

Figure 3. Distribution of 9 GCPs in experiment area.

Table 1. Camera parameters.

\begin{tabular}{ccc}
\hline Inner orientation elements & Radial distortion & Tangential distortion \\
\hline $\mathrm{f}=3.72193 \mathrm{~mm}$ & $\mathrm{R}_{1}=-1.35883 \times 10^{-3}$ & $\mathrm{~T}_{1}=-9.09776 \times 10^{-4}$ \\
$\mathrm{x}_{0}=3.15874 \mathrm{~mm}$ & $\mathrm{R}_{2}=-1.60514 \times 10^{-3}$ & $\mathrm{~T}_{2}=-1.13887 \times 10^{-3}$ \\
$\mathrm{y}_{0}=2.36905 \mathrm{~mm}$ & $\mathrm{R}_{3}=3.42187 \times 10^{-4}$ & \\
\hline
\end{tabular}

Firstly, the alignment of the acquired images was performed. The SfM algorithm comes into play by the detection of image feature points (edges or others geometrical features) by SIFT algorithm. The SfM algorithm provides the basic geometry/structure of the scene, through the position of the numerous matched features, in addition to camera positions and internal calibration parameters [18]. Then the dense point cloud was reconstruction from sparse points. After this step, fine topographic details available on the original images could be meshed, and also the texture was extracted to building the DSM.

Based on pix4D, we built the two following DSMs by high the overlap images with a computer which was equipped with the CPU of Intel E5-2620 v2, the video card of NvidiaQuadro K2000 and the 16 GB memory. The process completed in $2 \mathrm{~h}$.

1) The DSM of high cut slope without GCPs (see Figure 4);

2) The DSM of high cut slope with 4GCPS, including point 3, 6, 8 and 9 (see Figure 5). 


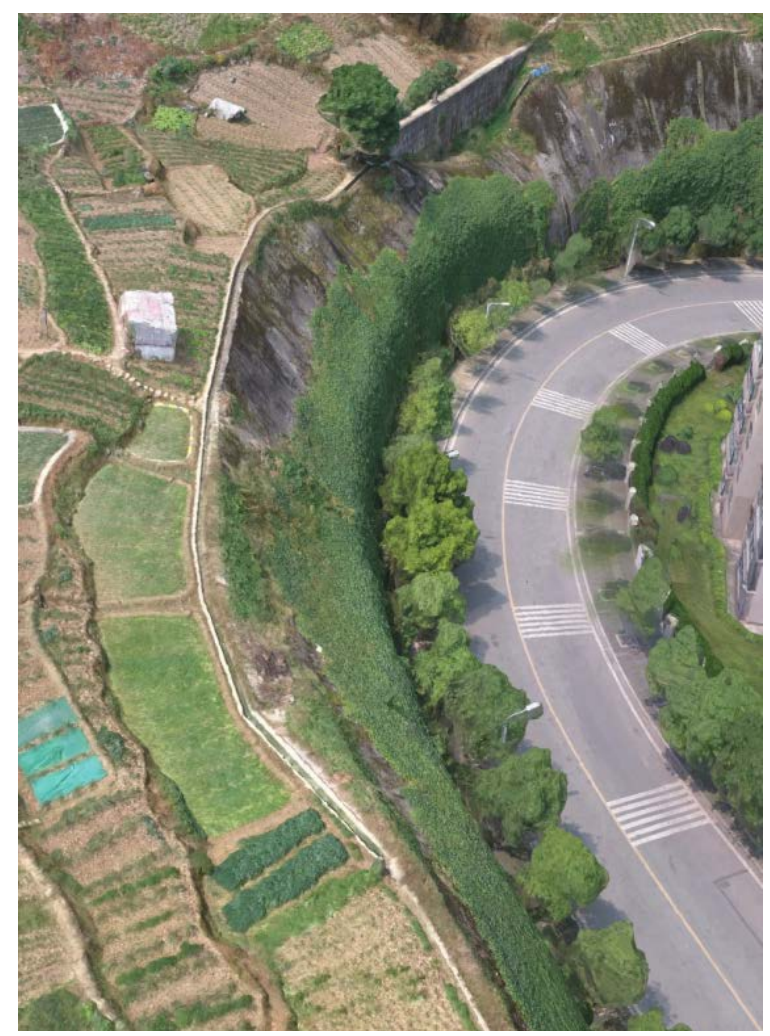

Figure 4. DSM without GCPs.

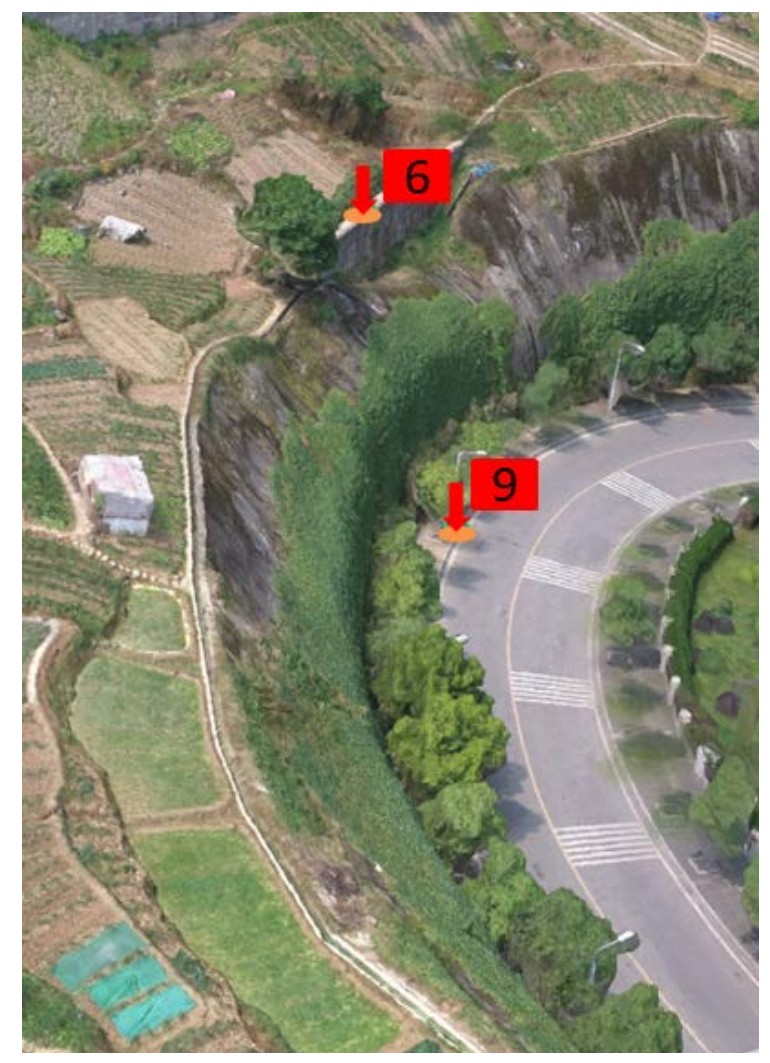

Figure 5. DSM with 4 GCPs. 


\section{Accuracy Assessment}

It is normal that using GCPs to improve the accuracy of DSM and some other raster data [19]. For the disaster, it remains that the GCP collection is a difficult and expensive task with HR data in remote and harsh environments or when cartographic or ground control data do not exist. In this context, the DSM without GCPs was proposed in order to eliminate the GCP collection task [17] [20]. The following text displays the accuracy of the different DSMs and puts forward a new way to estimate the DSM accuracy. It also verifies the feasibility of this proposal by comparing the accuracy between the DSMs.

\subsection{Accuracy of DSM with 4 GCPs}

The DSM of high cut slope was built by the high overlay images with the GCPs (point 3, 6, 8, 9). Then we measured the absolute accuracy of DSM by calculating the root-mean-square error (RMSE) of the other 5 points (point 1, 2, 4, 5, 7).

Table 2 presents the distortion of 5 check points. It can be seen that maximum distortion in XY direction is less than $0.1 \mathrm{~m}$ and the typical distortion in $\mathrm{Z}$ direction is about $0.05 \mathrm{~m}$. The RMSE is $0.076 \mathrm{~m}$ and $0.071 \mathrm{~m}$ in directions of $\mathrm{XY}$ and $\mathrm{Z}$ respectively. The experiment shows that the high overlay images obtained by photoing in direction of $45^{\circ}$ and $90^{\circ}$ are useful for building DSM perfectly with GCPs.

\subsection{Accuracy of DSM without GCPs}

Considering the 4 points (point 3, 6, 8, 9) locating at edge of the high cut slope, we defined them as check points to calculate the maximum distortion of the DSM.

Without GCPs, the DSM could have large distortion in direction of $\mathrm{Z}$ with adjusting by its own GPS of UAV. Given the large distortion, Table 3 only presents the distortion of 4 check points in directions of $\mathrm{X}$ and $\mathrm{Y}$. It can be seen that the maximum distortion was smaller than $5 \mathrm{~m}$ (see Table 3). The RMSE was about $4.4 \mathrm{~m}$, and it was defined as absolute accuracy. So the DSM without GCPs can be quickly located in approximate location when matching with other maps, like Google Earth.

We measured the distance between any 2 points from the 4 points in the model, then compared the fitted distance with true value to get difference, and this difference represents distortion degree of the model (the more difference, the larger distortion). In this paper, we defined the difference which was regarded as geometric accuracy of DSM. It can be seen from Table 4, when there is no GCPs, the geometric accuracy of high cut slope DSM is less than 1 percent. By comparing DSMs displaying in Figure 3 and Figure 4, and combining the geometric accuracy of the DSM, it can be found that the overall distortion of the DSM is small.

Table 2. Distortion of the check points in directions of XY and Z.

\begin{tabular}{ccc}
\hline Point name & $\mathbf{X Y}$ distortion $(\mathbf{m})$ & $\mathbf{Z}$ distortion $(\mathbf{m})$ \\
\hline 1 & 0.085 & 0.053 \\
2 & 0.046 & 0.118 \\
4 & 0.074 & 0.057 \\
5 & 0.074 & 0.078 \\
7 & 0.093 & 0.049 \\
\hline
\end{tabular}

Table 3. Distortion of check points directions of XY and Z.

\begin{tabular}{ccc}
\hline Point name & X distortion (m) & Y distortion (m) \\
3 & 2.707 & 2.465 \\
6 & 3 & 3.013 \\
8 & 2.708 & 4.279 \\
9 & 3.426 & 2.942 \\
\hline
\end{tabular}


Table 4. Distortion of distance.

\begin{tabular}{cccc}
\hline Point & $\begin{array}{c}\text { True distance } \\
(\mathbf{m})\end{array}$ & $\begin{array}{c}\text { Fitted distance } \\
\mathbf{( m )}\end{array}$ & $\begin{array}{c}\text { Distortion } \\
\mathbf{( m )}\end{array}$ \\
\hline $3-6$ & 60.395 & 61.293 & 0.898 \\
$3-8$ & 125.91 & 124.76 & 1.150 \\
$3-9$ & 67.059 & 66.282 & 0.777 \\
$6-8$ & 88.428 & 87.696 & 0.732 \\
$6-9$ & 26.574 & 26.675 & 0.101 \\
$8-9$ & 71.807 & 70.871 & 0.936 \\
\hline
\end{tabular}

\subsection{Result}

By calculating geometric accuracy, it can be easily seen that the DSM without GCPs can be used for disaster monitoring and emergency response and improve work efficiency. By analyzing the absolute and geometric accuracy of the DSM without GCPs, we can get the following results.

1) The DSM without GCPs can be quickly located in approximate location, and the error is about $4.4 \mathrm{~m}$;

2) Without GCPs, the DSM built by high overlay images which were obtained by vertical and inclined angle photography have a small distortion, and the relative accuracy is less than $1 \mathrm{~m}$ per $100 \mathrm{~m}$. So the DSM can be used to analyze high cut slope and the disaster.

\section{Analysis}

The DSM without GCPs can be used to analyze and monitor the high cut slope, because the accuracy of it which was less than $1 \%$ shows that the model was parallel to the real scene.

Figure 6 presents the land use/land cover (LULC) of the experiment field and it can be seen that the vegetable, road, bare land and building consist of the experiment field and the most of area is vegetable whose proportion is about 58\%. Figure 7 presents the LULC of high cut slope, and it was consisted of vegetable and bare land. Also, the vegetable consisted of the most area of the bottom. The slope is about 20 meters and besides the high building whose height was approximately 54 meters. So the building can be easily destroyed if the landslide happens.

The slope gradient map (see Figure 8) was obtained from DSM, it can be seen that the high cut slope have much larger gradient than the gradient of other place in experiment field. Then the high cut slope (see Figure 9) was extracted, and it can be calculated that the average gradient is about $\mathbf{4 7}$ degree, and the largest gradient is about 90 degree.

\section{Conclusions}

When geological disasters happen, stakeholders need to quickly evaluate disaster degree and plan emergency response projects. Because of low cost, flexible operation, real-time video transmission, detection of high-risk areas etc., UAVRS can be thought as the most feasible technology to obtain up-to-date images and subsequent data products like DSMs, which are critical for disaster monitoring and emergency. In this paper, differing from usual way of 3D reconstruction, in order to improve the efficiency of data production in disaster monitoring and emergency response, the precision of DSM about high cut slope by high overlay UAV images without GCPs was assessed.

Research results have proved feasibility of building DSMs from UAV images with high overlay rate, and these images are obtained from vertical and inclined angles. DSMs without GCPs are at the geometric accuracy of about 1 percent. According to absolute accuracy of the DSM, the site of disaster can be quickly located in approximate location. DSM can be extracted alone to analyze high cut slope and disaster, for example, disaster warning, extracting disaster area and disaster assessment. 


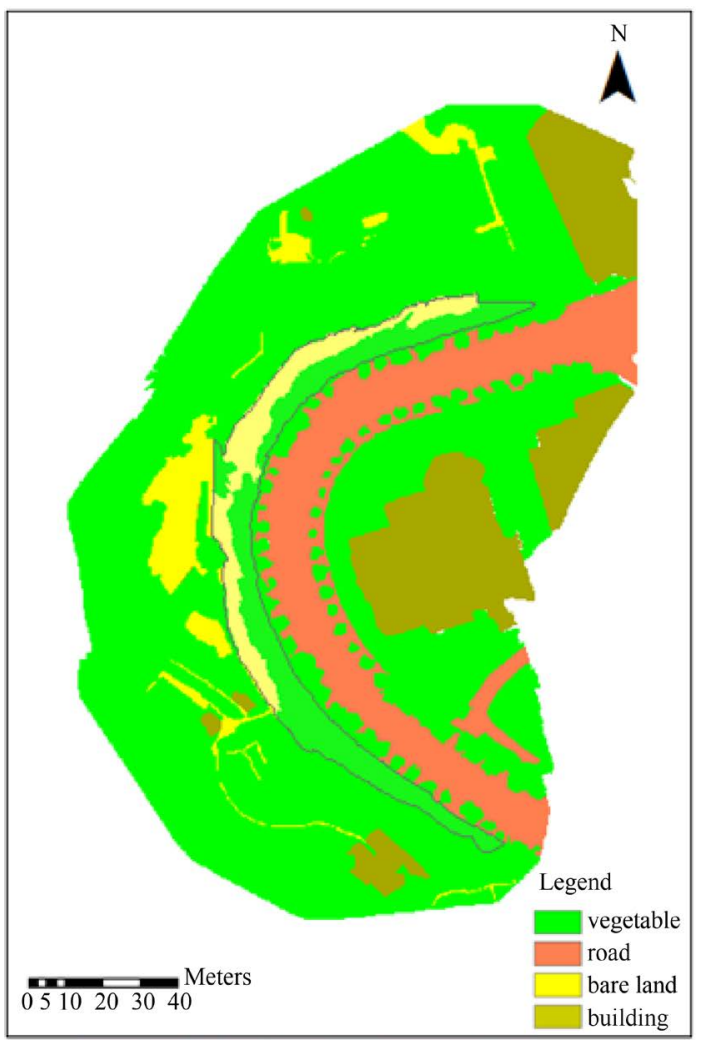

Figure 6. LULC map of experiment field.

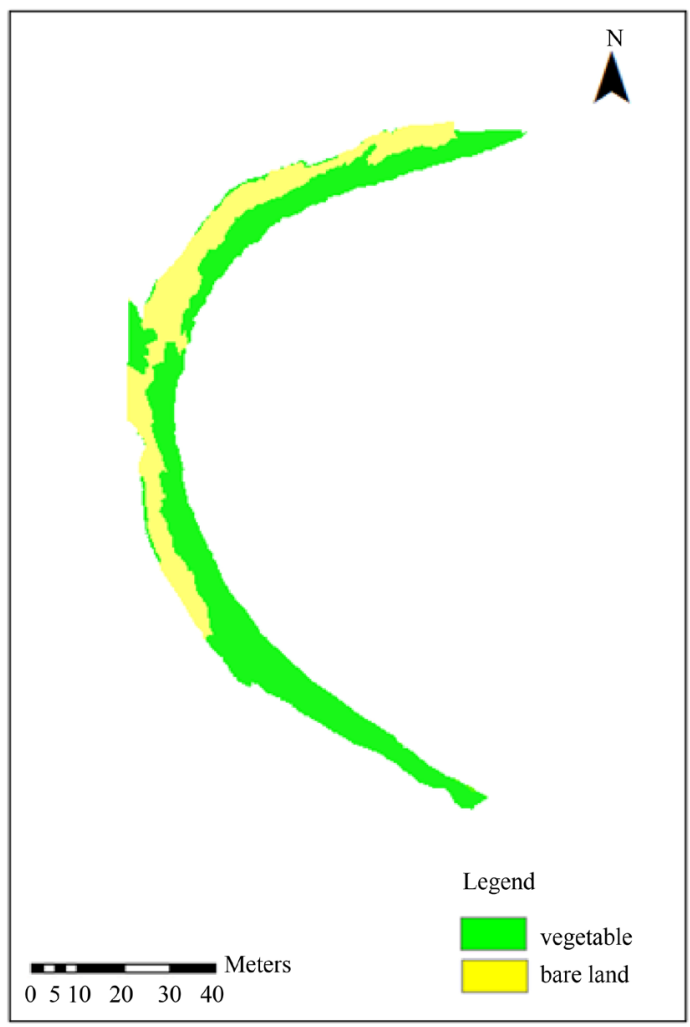

Figure 7. LULC map of high cut slope. 


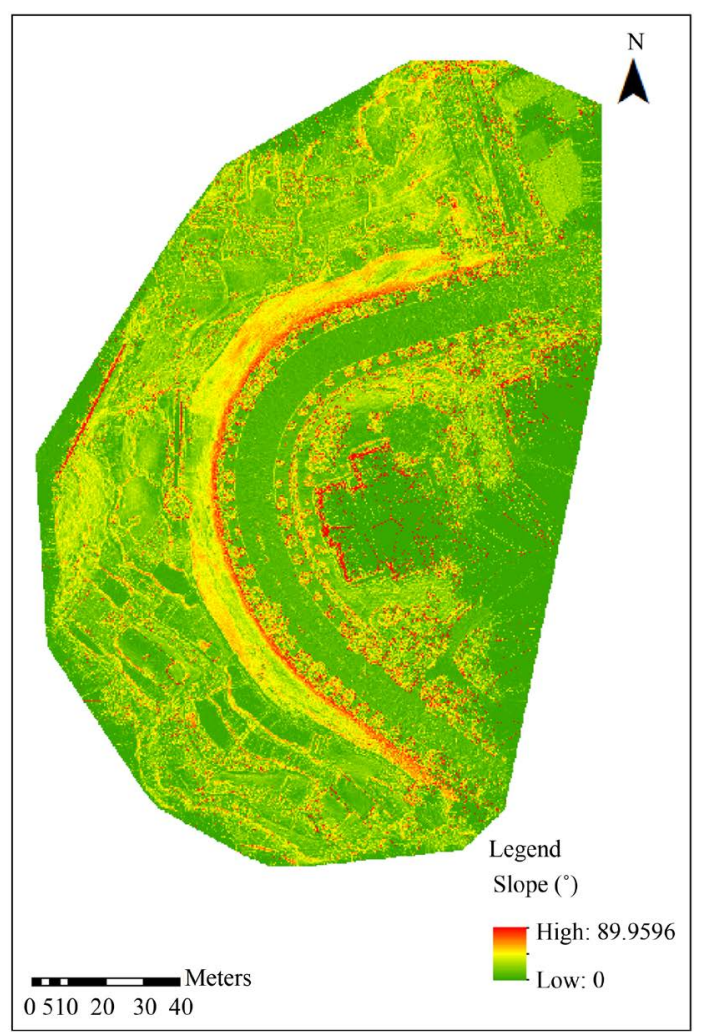

Figure 8. Elevation of experiment field.

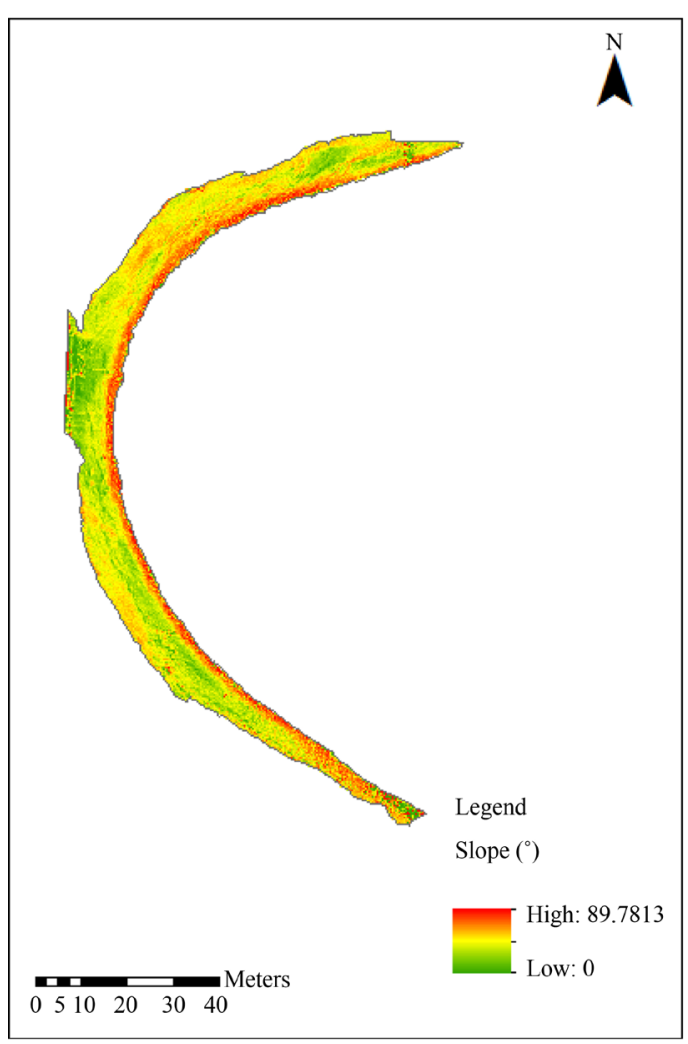

Figure 9. Elevation of high cut slope. 


\section{Acknowledgements}

This work is funded by State Grid Scientific Project 2016 (No. GCB17201600036) "Research on data processing theory and methods of the auxiliary lines selection based on satellite remote sensing image".

\section{Author Contribution}

Yumin Tan designed the study and reviewed the manuscript; Lingfeng He designed the experiment, processed the data and wrote the manuscript, and Linjie Bai helped field work in GCP collection.

\section{References}

[1] Luo, Y.H. and Wu, F.Q. (2004) The Basic Characteristics and Control Measures of High Cutting-Slope at the Three Gorges Reservoir. The Chinese Journal of Geological Hazard and Control, 15, 115-117. (In Chinese with English Abstract)

[2] Dong, J.Y., Yang, J.H., Wu, F.Q., Wang, D. and Yang, G.X. (2010) Research on Collapse of High Cutting Slope with Horizontal Soft-Hard Alternant Strata in Three Gorges Reservoir Area. Rock and Soil Mechanics, 31, 151-157. (In Chinese with English Abstract)

[3] Liu, B., Yin, K., Chen, L. and Du, J. (2010) Hazard Evaluation and Management System of High Cut Slope in the Three Gorges Reservoir Area Based on GIS. Journal of Highway and Transportation Research and Development, 27, 153-158.

[4] Li, S.J., Gao, H., Xu, D.M. and Meng, F.Z. (2012) Comprehensive Determination of Reinforcement Parameters for High Cut Slope Based on Intelligent Optimization and Numerical Analysis. Journal of Earth Science, 23, $233-242$. http://dx.doi.org/10.1007/s12583-012-0250-9

[5] Spreafico, M,C., Francioni, M., Cervi, F., Stead, D., Bitelli, G., Ghirotti, M., Girelli, V.A., Lucente, C.C., Tini, M.A. and Borgatti, L. (2016) Back Analysis of the 2014 San Leo Landslide Using Combined Terrestrial Laser Scanning and 3D Distinct Element Modelling. Rock Mechanics and Rock Engineering, 49, 2235-2251. http://dx.doi.org/10.1007/s00603-015-0763-5

[6] Hong, H.Y., Pourghasemi, H.R. and Pourtaghi, Z.S. (2016) Landslide Susceptibility Assessment in Lianhua County (China): A Comparison between a Random Forest Data Mining Technique and Bivariate and Multivariate Statistical Models. Geomorphology, 259, 105-118. http://dx.doi.org/10.1016/j.geomorph.2016.02.012

[7] Westoby, M.J., Brasington, J., Glasser, N.F., Hambrey, M.J. and Reynolds, J.M. (2012) Structure-from-Motion Photogrammetry: A Low-Cost, Effective Tool for Geoscience Applications. Geomorphology, 179, 300-314. http://dx.doi.org/10.1016/j.geomorph.2012.08.021

[8] Ciampalini, A., Raspini, F., Frodella, W., Bardi, F., Bianchini, S. and Moretti, S. (2016) The Effectiveness of HighResolution LiDAR Data Combined with PSInSAR Data in Landslide Study. Landslides, 13, 399-410. http://dx.doi.org/10.1007/s10346-015-0663-5

[9] Nebiker, S., Annen, A., Scherrer, M. and Oesch, D. (2008) A Light-Weight Multispectral Sensor for Micro UAVOpportunities for Very High Resolution Airborne Remote Sensing. International Archives of the Photogrammetry, Remote Sensing and Spatial Information Sciences, 37, 1193-1198.

[10] Gonzalo, P. (2015) Overview and Current Status of Remote Sensing Applications Based on Unmanned Aerial Vehicles (UAVs). Photogrammetric Engineering \& Remote Sensing, 81, 281-329. http://dx.doi.org/10.14358/PERS.81.4.281

[11] Li, D.R. and Li, M. (2014) Research Advance and Application Prospect of Unmanned Aerial Vehicle Remote Sensing System. Geomatics and Information Science of Wuhan University, 39, 505-512.

[12] Li, X.H., Luo, X.L. and Gong, X.C. (2012) Application of Aerial Survey Technology by Unmanned Aerial Vehicle in Measurement and Analysis for Slump Steep Sections of Highways. Technology of Highways and Transport, 4, 49-53. (In Chinese with English Abstract)

[13] Konstantinos, G., Katerina, K., Nikolaos, D., Nikolaos, A., Ioannis, K. and Nikolaos, S. (2015) Active Landslide Monitoring Using Remote Sensing Data, GPS Measurements and Cameras on Board UAV. Proceedings of SPIE, 9644.

[14] Darren, T., Arko, L. and Steven, M. (2015) Time Series Analysis of Landslide Dynamics Using an Unmanned Aerial Vehicle (UAV). Remote Sensing, 7, 1736-1757. http://dx.doi.org/10.3390/rs70201736

[15] Zhan, Z.Q. and Lai, B.H. (2015) A Novel DSM Filtering Algorithm for Landslide Monitoring Based on Multiconstraints. IEEE Journal of Selected Topics in Applied Earth Observations and Remote Sensing, 8, 324-331. http://dx.doi.org/10.1109/JSTARS.2014.2319855

[16] Liu, Y., Li, Y.X. and Tong, L. (2012) Geometric Correction for Unmanned Aerial Vehicle Remote Sensing Image without Ground Control Points. Bulletin of Surveying and Mapping, 7, 57-59. (In Chinese with English Abstract) 
[17] Toutin, T., Schimitt, C.V. and Wang, H. (2012) Impact of No GCP on Elevation Extraction from World View Stereo Data. ISPRS Journal of Photogrammetry and Remote Sensing, 72, 73-79. http://dx.doi.org/10.1016/j.isprsjprs.2012.05.009

[18] Francesco, M., Marco, D., Mario, G., Francesco, S., Stefano, F. and Giovanni, G. (2013) Using Unmanned Aerial Vehicles (UAV) for High-Resolution Reconstruction of Topography: The Structure from Motion Approach on Coastal Environments. Remote Sensing, 5, 6880-6898. http://dx.doi.org/10.3390/rs5126880

[19] Birute, R., Tautvydas, B., Silvija, G., Edita, J. and Vladislovas, C.A. (2015) The Surface Modelling Based on UAV Photogrammetryand Qualitative Estimation. Measurement, 73, 619-627. http://dx.doi.org/10.1016/j.measurement.2015.04.018

[20] Toutin, T. (2012) Radarsat-2 DSM Generation with New Hybrid, Deterministic, and Empirical Geometric Modeling without GCP. IEEE Transactions on Geoscience and Remote Sensing, 50, 2049-2055. http://dx.doi.org/10.1109/TGRS.2011.2170693

\section{Submit or recommend next manuscript to SCIRP and we will provide best service for you:}

Accepting pre-submission inquiries through Email, Facebook, LinkedIn, Twitter, etc.

A wide selection of journals (inclusive of 9 subjects, more than 200 journals)

Providing 24-hour high-quality service

User-friendly online submission system

Fair and swift peer-review system

Efficient typesetting and proofreading procedure

Display of the result of downloads and visits, as well as the number of cited articles

Maximum dissemination of your research work

Submit your manuscript at: http://papersubmission.scirp.org/

Or contact ars@scirp.org 